\title{
HANS OF THE OTTOMAN PERIOD: AN ANALYSIS OF THE SPATIAL CONCEPT IN FUNCTION OF A MODERN TOURIST PURPOSE
}

\author{
Petar Namicev \\ University of Goce Delcev Shtip, Republic of Macedonia \\ e-mail:petar.namicev@ugd.edu.mk
}

\section{Professional Paper doi:10.5937/jouproman5-15072}

\begin{abstract}
The highest developed form of a spatial concept of ainn in the urban area of the Ottoman period is the rectangular form of the spatial organization of the hans from the 15 th and the 16th centuries. The most important examples are Kurshumlihan, Sulihan and Kapan han in the old bazaar in Skopje, which are part of a complex spatial system of the historical part of the city. According to the urban concept of the Ottoman builders, a group of public buildings has been formed, where mosque, bedesten, hamam, etc. appear beside another. Spatial analysis of auxiliary rooms and overnight accommodation, or open spaces (atrium, porch) has a certain specific ratio. The experience of the organization from historical buildings is a valuable experience in terms of balancing different contents of the used space, its purpose and adjustment to the current needs of the object. The experiences from the study of certain spatial elements of the hans and from the analysis of the current tourism development in which they are included, can be applied in the concept of modern tourist objects.
\end{abstract}

Key words: Han, tourism, protection, ambient, atrium

\section{Introduction}

The Hans are objects that were primarily used for the purpose of staying on the caravans that passed through the Balkans during the Ottoman rule, in order to protect the animals and the goods they carried. The han is a massive structure with a square ground plan, with atrium, a sadrvan, and a fountain in the center, with two - storey porch (Pavlov 2008). The ground floors were in the function of storing goods, while on the first floor they served for rest, overnight, where the premises had fireplaces. In the historical center of Skopje, the most significant buildings from this period are the Kurshumlihan (XVI c), Sulihan (XV c) and Kapan han $(\mathrm{XVc})$, which represent a rare preserved whole that is incorporated in the structure and function of the bazaar and the old city core. These objects represent a rare sample of preserved and preserved objects, which besides the architectural and constructive values, through the experience so far, have a great importance for the development of tourist concepts. The hans were usually placed at a distance of $30-40 \mathrm{~km}$, as far as they could travel in one day (Walterberger, 2014) or on a one-day trip from one to another an. In the period until the middle of the 16th century, thirteen inns are mentioned in Skopje. The hans were built by rich individuals or civil servants (Богојевиќ 2014). In addition to the hans, which were from a closed system on the outer walls, they relied on shops (Sulihan with 20 stores).

Apart from the fact that the hans provided safe stay for the passengers and the goods, they also used to store the goods (Kapan an) and for the purpose of trade. At the entrance was a room for an angjiah, who controlled the entrance and the number of passengers. The existence of this type of han, which are in the category of complex type, speaks about the developed trade in the Balkans in the 16th century, as well as the development of the bazaar in the same period. 
On these objects conservation was carried out, with preventive protection realized after 1963 (Ničota 1983) on Kursumlian, while Kapan han was restored in the period 1919-1920, and in the period from 1963 - 1973, (Ničota 1983). In the atriumcentered space, a fountain was lit with water to refresh the passengers in the summer. The quality of the architectural spatial solution was achieved by separating a special storage space for the stables for keeping the livestock goods. This space is built on the north side (Kurshumlihan) with a specially built atrium area and a separate entrance from the outside, or with direct entrance from the atrium area (Sulihan) or as part of the ground floor premises (Kapan han). In the area of the barn (horsehouse) alongside the walls, on both sides, stone foundations are placed on the feeding sides of the goods (Bogojevic 2014). In this way, the hans formed a functional and aesthetically balanced structure, which was held and proved to be resistant to many changes in the period of its existence to date.

\section{Purpose of hans}

According to the conditions in which the hans were created in the 15th and 16th centuries, two spatially separated purposedesigned useful surfaces were created, for the stay of the goods and the people from the caravans. In order to meet the needs of the caravans that passed from the Balkans, where Skopje was a settlement with a formed structure of buildings, residential facilities were built according to the criteria of the Ottoman way of treating the space.

Caravans needed the safe accommodation of the goods and accommodation of passengers for rest. The objects had the most commonly concept of grouping the rooms on the ground floor, with horseriding stables where the horses were placed and fed, as part of the building or with a separate singular part - a space that was connected to the main building. From the very needs came the spatial conception of the central atrium part, and the setting of the premises around. There were created equal conditions for stay, with even lighting and access to every room.

The spatial concept has evolved over several centuries adapted to the needs of the caravans and has reached a high level of simplicity and perfection of the form. The constructive possibilities, the stylistic expressive means, the aesthetic expression translated into details that are recognizable for each object have been successfully combined. In this way, an authentic architectural form was created with values that existed over a longer period of time.

The functional concept of the hans needed to satisfy the primarily functional needs for security, by which one controlled input with a large port was practiced. More rarely, a secondary entrance was constructed, either as an auxiliary or for entering the goods. The simplicity in meeting the functional needs was expressed in the shape of the object. Connection with the main roads, the markets that were frequent spaces and other religious (mosques) and public buildings (bedestens, shops, baths, etc.) formed a concept of interconnected objects, as part of the historical core of the city. The immediate vicinity of the city and the existing communications enriches the attractiveness of the hans, a place that is still applied today in the modern concepts of this type of objects. Directly setting up stores to the outer walls of the hans creates an ambient concept and directly involves the han in the authenticity of the bazaar and its dynamic structure. 


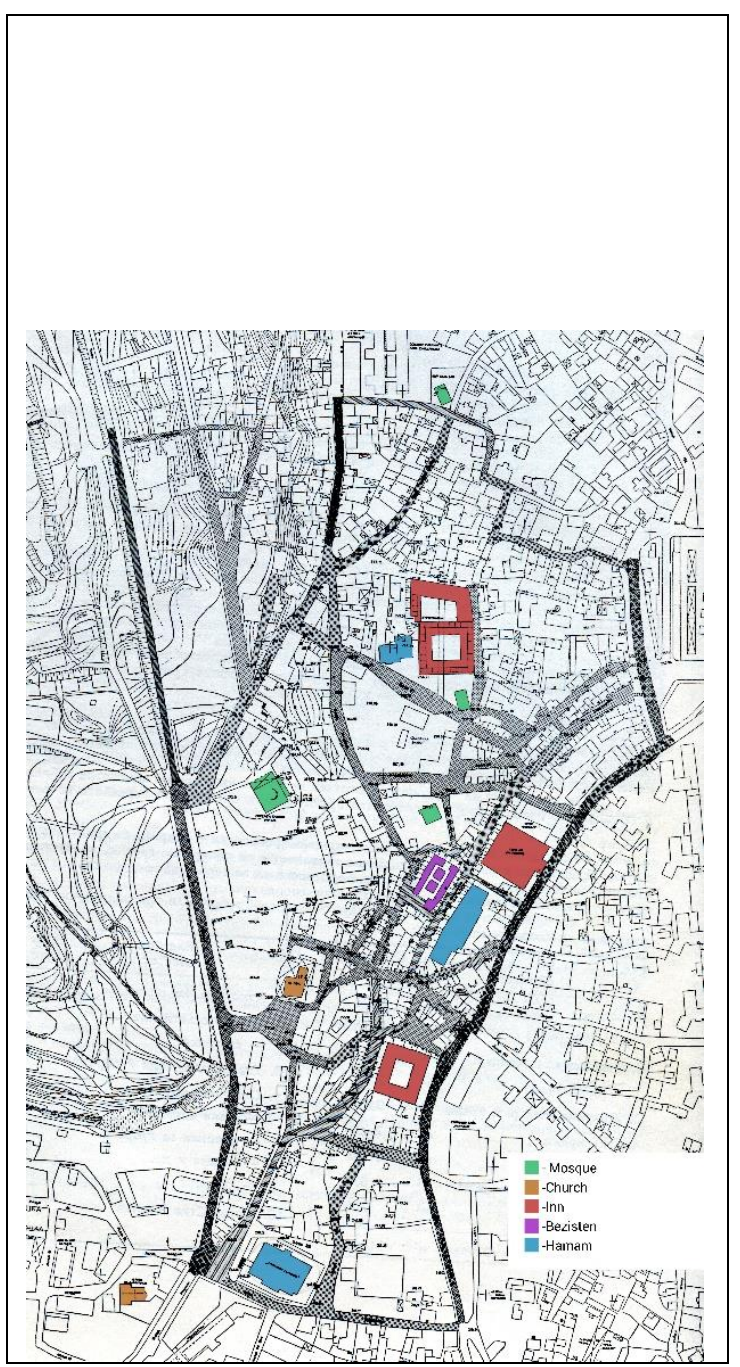

Fig.1. Plan of Skopje bazaar with the monuments from ottoman period, including: Kurshumlihan, Sulihan and Kapan han.

Satisfaction of the basic elements of functionality confirms a certain current concept, which can be used in the methodological sense when creating modern catering facilities. The factors of functional satisfaction according to actual needs mean the setting of priority tasks with certain spatial values.

When dimensioning the hans beside the spatial constructive elements, where the arched construction dominates, decorative elements with a certain rhythm are used. The application of the brick not only as a decorative element, but also as a constructive one, allows visibly to be imposed, beside the stone, as a dominant decorative element that affects the aesthetics of decoration on the surfaces.
The rigid division with the structural elements, which creates a certain rhythm, in addition to the static justification, contributes to the aesthetic complexity of the surfaces of the objects.

The entire decorativeness of the space is oriented towards the inner atrium space, while the external walls are processed as secondary, on which the structures of the stores in the bazaar are relying. The decoration is made of high quality processed stone and bricks.

Regarding the space they occupy, in terms of the number of useful premises and the number of shops in the bazaar, these objects are dominant and monumental objects, besides the mosques that are placed in the dominant places in the surroundings. According to the needs of the bazaar and the city, the hans developed in a continuous long time process and through these three facilities represents a true representative of the values of the Muslim architecture.

When designing the architectural concept, a spatial ambience was created, which depicts a certain security in the space, as one component that was to be satisfied for the survival of the hans. The vital function of the hans is in addition to the safety and location directly incorporated space in the core of the bazaar where a large number of craftsmen and traders are in operation. The need for overnight accommodation has developed these facilities to become part of the structure and function of the city. In the hans there was a controlled entrance, which was shaped by large gates, through which the carts could pass through caravans, with a capacity of around 100 people.

The spacious concept of the han beside the structure of separate rooms, is equipped with small windows, which are provided with bars, and each room has a solidly placed entrance provided from the inside (porch).

The very construction of massive stone walls thicker than one meter, in addition to satisfying the constructive norms, creates a certain security of the interior, and a certain safety for fire protection. 
The internal space of the separate rooms is shaped according to the needs of the visitors, with internal processing of the walls, similar to the surfaces of the interior. There is a fireplace in each room (Kurshumlihan), because of low temperatures, and also for lighting of the space. Although the separate rooms have a small useful area, they are evenly functionally equipped with the same elements. The necessity of the interior elements of furniture was satisfied with the formation of openings in the walls-cupboards, as well as wooden works of coffins and other objects. In this way, the elements of the authentic image of the interior have not been preserved because of the application of the tree and the permanent restoration of the buildings from the 15 th to the 20th century.
The interior ceiling surfaces are resolved according to the construction, which is provided with semi-cylindrical arches, which are attached to them in the area of the porch. In this way, congruent forms of shaping the interior space, which complement the massive construction with aesthetically shaped details, create the constructive concept of the object with stylish decoration. Colonnades of pillars with varnishes create a harmonious and intimate atmosphere, while decorative walls are derived from high quality chiseled alternating rectangular stone and brick, and small shaped domes (Kurshumlihan).

\begin{tabular}{|c|c|c|c|}
\hline Han & Kurshumli Han & Suli Han & Kapan Han \\
\hline & 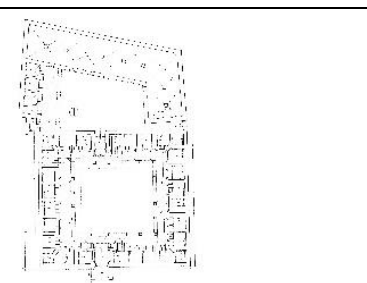 & 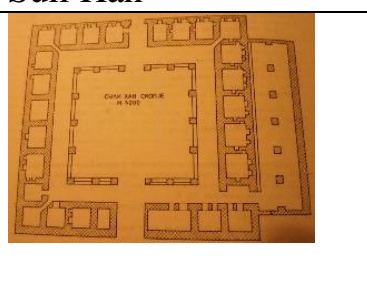 & 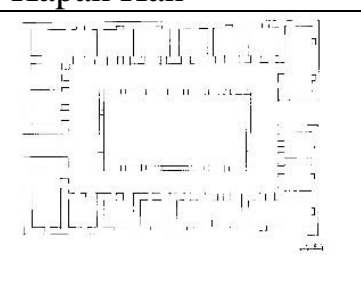 \\
\hline Total space & $\begin{array}{l}1929 \mathrm{~m}^{2} \text { (ground floor) } \\
+1553 \mathrm{~m}^{2} \text { (upper floor) } \\
1489 \mathrm{~m}^{2} \text { (stable) } \\
2800 \mathrm{~m}^{2} \text { (used space) }\end{array}$ & $\begin{array}{l}1617 \mathrm{~m}^{2} \text { (ground floor) } \\
+1232 \mathrm{~m}^{2} \text { (кат) } \\
262 \mathrm{~m}^{2} \text { (stable) } \\
2101 \mathrm{~m}^{2} \text { (used space) }\end{array}$ & $\begin{array}{l}1326,8 \mathrm{~m}^{2} \text { (ground } \\
\text { floor) }+ \\
1108,44 \mathrm{~m}^{2} \text { (upper } \\
\text { floor) } \\
1086 \mathrm{~m}^{2} \text { (used space) }\end{array}$ \\
\hline Used space/rooms & $\begin{array}{l}484 \mathrm{~m}^{2} \text { (ground floor) } \\
+484 \mathrm{~m}^{2} \text { (upper floor) }\end{array}$ & $\begin{array}{l}431 \mathrm{~m}^{2} \text { (ground floor) } \\
+464,8 \mathrm{~m}^{2} \text { (upper } \\
\text { floor) }\end{array}$ & $\begin{array}{l}369,6 \mathrm{~m}^{2} \text { (ground } \\
\text { floor) }+ \\
403,2 \mathrm{~m}^{2} \text { (upper floor) }\end{array}$ \\
\hline$\%$ & $24,2 \%$ & $25,9 \%$ & $27,9 \%$ \\
\hline Corridors/porch & $376 \mathrm{~m}^{2}+25,8 \mathrm{~m}^{2}$ & $285 \mathrm{~m}^{2}$ & $374 \mathrm{~m}^{2}$ \\
\hline$\%$ & $16,2 \%$ & $18,0 \%$ & 28,15 \\
\hline $\begin{array}{l}\text { Walls/ } \\
\text { construction }\end{array}$ & $561 \mathrm{~m}^{2}$ & $516 \mathrm{~m}^{2}$ & $365,44 \mathrm{~m}^{2}$ \\
\hline$\%$ & $31,4 \%$ & $31,5 \%$ & $27,9 \%$ \\
\hline atrium & $508 m^{2}+415 m^{2}$ & $385 \mathrm{~m}^{2}$ & $218,36 \mathrm{~m}^{2}$ \\
\hline$\%$ & $28,4 \%$ & $24,6 \%$ & $16,1 \%$ \\
\hline $\begin{array}{l}\text { Number of rooms in } \\
\text { han }\end{array}$ & $\begin{array}{l}28 \text { (ground floor) }+32 \\
\text { (upper floor) }\end{array}$ & $\begin{array}{l}27 \text { (ground floor) }+30 \\
\text { (upper floor) }\end{array}$ & $\begin{array}{l}20 \text { (ground } \\
\text { floor)+22(upper floor) }\end{array}$ \\
\hline $\mathrm{m}^{2} /$ room & $17,3 \mathrm{~m}^{2}$ & $16,6 \mathrm{~m}^{2}-18,5 \mathrm{~m}^{2}$ & $16,8 \mathrm{~m}^{2}$ \\
\hline Inside high & $3,45 \mathrm{~m}$ & $3,85 \mathrm{~m}$ & $4,15 \mathrm{~m}$ \\
\hline Citizens XVI-XIX c & $30-32.000$ & $30-32.000$ & $30-32.000$ \\
\hline $\begin{array}{l}\text { City bazar - number } \\
\text { of shops }\end{array}$ & 2.150 & 2.150 & 2.150 \\
\hline
\end{tabular}

Fig.2.Comparative analysis of architectural space of the hans 


\section{System of applied protection}

During the period of existence of the hans, they suffered periodic repairs to the construction or certain decorative elements, without breaking the basic concept of the object. Conservation measures are needed from the aspect of preventive care to prevent further damage. Although total reconstructions have been performed in the last 50 years and after each rehabilitation, the facilities are maintained by constantly monitoring their condition. This is especially important due to the active adaptation of the space with a modern trade, educational or museum purpose.

Recent reconstruction after the earthquake in 1963 was carried out on Kurshumli han
(1965), Suli han (1965) and Kapan han (1971), thus obtaining today's appearance.

The process of protection needs to be practiced continuously, due to the many changes that arise with its adaptation. During the use of objects, they are susceptible to multiple changes and adaptations, it is necessary to make continuous analyzes to meet the needs for modern space use. In order to take into account the authentic appearance, protection of the constructive vital elements, respect the functionality of the space, to respect the legal measures for promotion of the monument values, and to be included in the cultural and tourist offer.

\begin{tabular}{|l|l|l|}
\hline Kurshumli Han & Suli Han \\
\hline & & \\
\hline Brick/stone & & \\
\hline Lime mortar & Brick/ stone & \\
\hline Arch & Lime mortar & Brick/Stone \\
\hline lead/tiles & Arch & Opus cloisonné \\
\hline Decorative facade & Tiles & Columns, Arch \\
\hline Brick/stone & Decorative façade & Tiles \\
\hline Atrium & Brick/stone & Binimal decorative facade \\
\hline & Atrium & Brick/stone \\
\hline 3.Con & Atrium \\
\hline
\end{tabular}

Fig. 3. Comparative analysis of construction of the hans

\section{Factors of influence}

When designing the objects, there are certain factors of influence for their integration into the modern urban concept and tourist development of the city.

1. According to the analyzes of comparing their useful surface, they sufficiently satisfy certain modern spatial needs of alternative space adaptations. In doing so, the basic concept of the hans is respected in the context of the interventions that are carried out, during the adaptation, and are related to modern installations, treatment of the useful space, application of modern materials, etc.

2. Enspecting the authenticity of the objects, ensures a certain level of conservation of the visual effects and contribution to the cultivation of landscape environmental values. 
3. From the period of construction of objects (15th and 16th c.), their use and rebuilding in the 19th and 20th centuries, the buildings are transformed to some extent in relation to the dimensions, but retain the recognizable form.

4. With the large number of interventions in the architectural concept of the buildings certain changes occur in defining the structure of the wall surfaces and their influence on the effect of defining the decoration. By emphasizing a certain structure of the structural elements, various decorative and aesthetic effects are achieved, which contribute to the stylistic recognizability of the object.

5.Consumer interventions of a smaller scale or complete from the 20th century largely affect the authenticity of the building and the useful space. Primary goals are structural stability, preserving as much percentage of authentic elements as possible from the construction or decoration, which affects the recognizability of the object.

6 . The constant unchanged location of the hans creates a certain relation to the surrounding of the historical buildings, thus adapting to the ambience in the city. In this way, the role of historical objects is to connect and be part of the modern needs of the city.

7. In addition to the preserved original appearance, despite the large number of interventions, the purification of the traditional form of the historical style has been achieved by attaining a high level of harmonious aesthetics of spatial shaping.

\begin{tabular}{|c|c|c|}
\hline 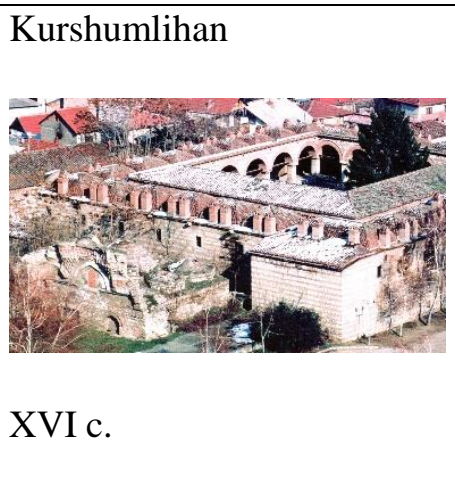 & 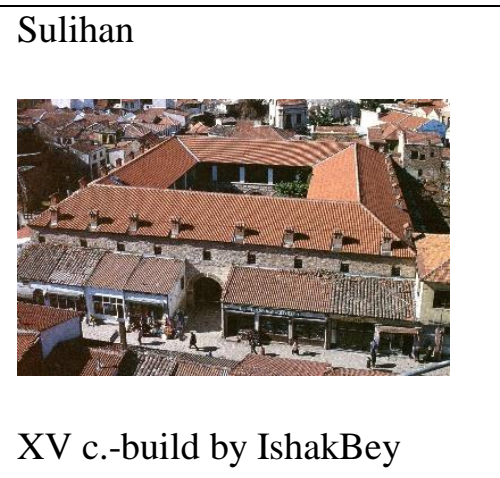 & XV c.-build by Ishak Bey \\
\hline $\begin{array}{l}1787 \text { - prison } \\
\text { Late XIX c. -reconstruction } \\
\text { Sec.half of XIX c. -prison } \\
\text { 1904-1912- Inn } \\
\text { After First world war- } \\
\text { weapon depot } \\
\text { 1955-lapidarium } \\
\text { XIX c.- covered with lead } \\
\text { XX c. - recovered with tiles } \\
\text { after1963- reconstruction }\end{array}$ & $\begin{array}{l}\text { 1555 - earthquake } \\
\text { 1689.- restore } \\
\text { XVII.-covered with lead } \\
\text { XVIII- covered with tiles } \\
\text { After late XIX c.-warehouse, } \\
\text { craft shops } \\
\text { End of XIX c- storehouse } \\
\text { Beg. of XX century-milk store } \\
\text { First half of XX c.-residence } \\
\text { after1963- earthquake- } \\
\text { destroyed } \\
\text { after1965- restored }\end{array}$ & $\begin{array}{l}\text { XV c. - Trading Inn } \\
1555 \text { - earthquake } \\
1689 \text { - fire } \\
\text { 1963- earthquake } \\
1919-1920 \text { rebuild at first floor } \\
\text { Beg of XX c. - -restored with } \\
\text { upper floor }\end{array}$ \\
\hline Mid XX c. rebuild & 1964 -rebuilding & 1971-1973 restoration \\
\hline $\begin{array}{l}\text { Today- museum, lapidarium, } \\
\text { office }\end{array}$ & $\begin{array}{l}\text { Today -Art academy and } \\
\text { Museum of old bazaar }\end{array}$ & Today- shopping center \\
\hline Two entrances & Two entrances & Two entrances \\
\hline Two open courtyards & One open courtyard & One open courtyard \\
\hline $\begin{array}{l}28 \text { (ground floor) } \\
32 \text { rooms(upper floor) }\end{array}$ & $\begin{array}{l}27 \text { rooms (ground floor) } \\
30 \text { rooms(upper floor) }\end{array}$ & $\begin{array}{l}20 \text { (ground floor) } \\
24 \text { (upper floor) }\end{array}$ \\
\hline
\end{tabular}

Fig.4. Chronology and conservation of historic buildings - hans 


\section{Analysis of further measures}

It is very important to determine the directions and priorities of the foreseen factors in order to specify the following activities for treating the hans.

The location of the hans and their surrounding sallows for a consistency of the whole of historic buildings, ie the existence of a continuity of preservation of the historical core of the city.

There cognizability of the place depends on the treatment of the monument and its in corporation in contemporary needs, which are the result of many influential factors in the urban concept.

If the directions for long-term development of the space around the hans should not be compromised in violation of the authenticity of the object. In particular, care should be taken of the internal arrangement, decoration and aesthetic form, aspart of a study and a project for the degree of anticipated intervention.

Since the period of the last conservation interventions in the second half of the 20th century, the condition of the hans is stable. Preventive protection measures require constant monitoring in case additional timely measuresare under taken, which should be part of the annual programs of the municipality, that is, the responsible organizations, in order to include the facilities actively in the modern tourist offers.

\begin{tabular}{|l|l|l|}
\hline Kurshumlihan & Kapan han \\
\hline $\begin{array}{l}\text { Transformation with additional } \\
\text { purpose and no additional } \\
\text { shops from outside }\end{array}$ & $\begin{array}{l}\text { Transformation with additional } \\
\text { shops outside of the building }\end{array}$ & $\begin{array}{l}\text { Often transformation of interior } \\
\text { spacewith additional shops } \\
\text { outside of the building }\end{array}$ \\
\hline $\begin{array}{l}\text { Flexible interior space, with } \\
\text { multi functional purpose }\end{array}$ & $\begin{array}{l}\text { Flexible interior space with } \\
\text { contemporary treatment }\end{array}$ & $\begin{array}{l}\text { Flexible Interior multy purpose } \\
\text { space }\end{array}$ \\
\hline $\begin{array}{l}\text { Minimal interior decoration } \\
\text { fimple geometric constructive } \\
\text { forms- arch }\end{array}$ & $\begin{array}{l}\text { Simple geometric constructive } \\
\text { forms }\end{array}$ & $\begin{array}{l}\text { Expressed constructive } \\
\text { elements, columns }\end{array}$ \\
\hline
\end{tabular}

Fig.5. The impact of the internal decoration on the values of the monument

Through the care of the monument and its maintenance from various aspects, it influences the development of cultural tourism in the region.

-In the longer term, the strategy for identifying the population and tourists with historical buildings should be developed in order to contribute to their further affirmation. These facilities represent a center for promotion of certain cultural values in the city, ie to develop a strategy for implementing active cultural tourism, which is part of the historical core of the city.

-In the existence of the facilities throughout the entire historical period, large spatial interventions and deviations from the authentic form were not carried out, which did not greatly influence the preservation of the authenticity of the inner setting. This has created a continuity of recognition and fostering of ambient values in and out of the hans. 
-The purpose of hans space over different periods is transformed, with a change from the basic function. The modern way of adaptation allows to adapt contemporary function in a historical monument, such as for museum, lapidarium space, administrative function and commercial space. It allows the active space to fit into an authentic historical building, and at the same time to ensure decent maintenance of the building itself.

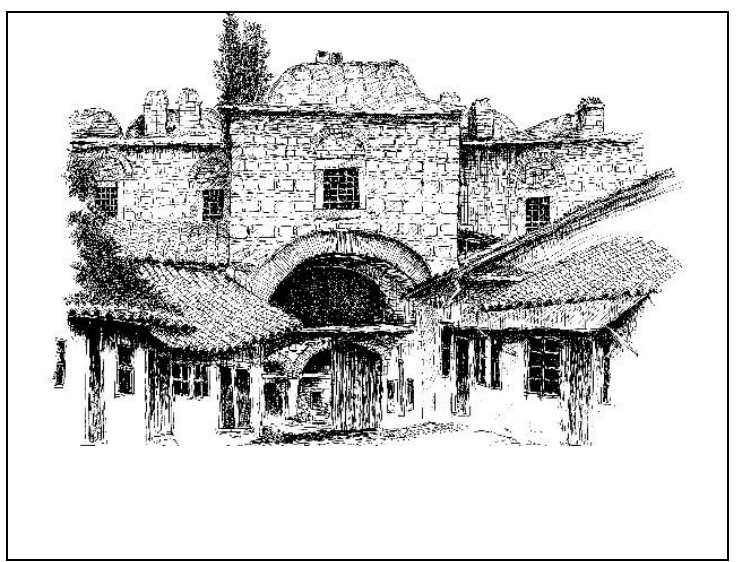

Fig.6. Main entrance with shops from bazaar, Kurshumlihan, Skopje, $19^{\text {th }}$ century

\section{Capacity for touristic purposes}

In case of anticipating the purpose of the hotel accommodation facility it is necessary to foresee certain measures of preventive protection with exactly specified degrees of intervention, because a large number of modern installations are covered, for arrangement of a high category facility. Based on the existing dimensions of the facilities and their ratio, it is a valuable experience, which can be applied in the design of modern hotel spaces. Authenticity of the hans space creates conditions for their adaptation in accommodation capacity, where it is necessary:

- To preserve the authenticity of the objects, with constructive stability, the use of authentic materials, and the original concept for accommodation purposes
-To adapt the premises according to the contemporary needs of tourism, hotel accommodation, which would provide exclusive spatial accommodation facilities

- To anticipate all modern conditions of hotel accommodation (installations, selection of materials), which is not to be disturbed, the basic concept of the visual aesthetics of the object and the landscape experience

- Space is projected according to the legal and world regulations of accommodation facilities of the highest category

-The size of the facilities with the envisaged useful area creates the conditions for forming a functional and modern tourist concept

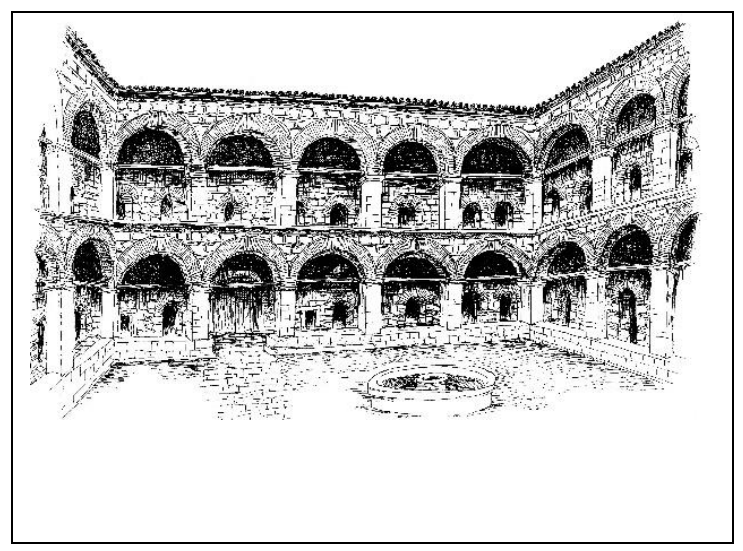

Fig.7. Interior view, Kurshumlihan

\section{Conclusion}

The ancients developed over a long period of time, perfected their purpose and spatial possibilities, which were connected with the development of the bazaar, the development of the city's economy and the needs of the caravans that passed through the Balkans. The three inns in Skopje represent a rare example of concentrated preserved objects within the historical core, with insignificant changes in the construction, spatial structure and interior appearance. 
According to written sources, the volume of hans has not been transformed to a great extent, but has retained its form.

The analysis of the factors influencing the urban context of the city suggests that these monuments need to have treatment for their protection in order to preserve the monumental properties, but it is necessary to constantly adjust the changes to the modern urban concept of the city.

Modern urbanism needs to have a special treatment for historical buildings, according to the current legal regulations, where it is necessary to take into account social, historical, economic, climatic, urban, etc.

Particularly important is the approach of analyzing the factors that influence tourism, where the connection of historical objects, as monuments of special importance, have high values. They are treated as monuments, in tourist offers that are connected, as carriers of certain routes, with a central place in the city and in the region.

\section{Reference}

[1] Arsovski, T. (1971): Stara skopska carsija,Skopje, Svetlost

[2] Bogojević, K. L. (2014): Osmanliski spomenici vo Skopje, Skopje, Tabernakul

[3] Ničota, N. (1983): Konstruktivno i seizmičko obezbeduvanje na nedvižni spomenici na kulturata, Kulturno nasledstvo, XVIII, Skopje, 194

[4] Ničota, N. (1983) Kapan an, Skopje, Kulturno nasledstvo, XVIII, Skopje, 203-204

[5] Pavlov, Z. Petkova R. (2008): Macedonian Cultural heritage: Ottoman monuments, Office in Venice, UNESCO

[6] Čipan, B.(1955): Zaštita spomenika culture u R. Makedoniji, Ansambl Kuršumli - hana u Skoplju (han, džamija,amam), Savezni Institut za zaštitu spomenika kulture, Zbornik zaštite spomenika kulture $I V-V$, Beograd, 319-322

[7] Waltenberger, T. (2014): The Ottoman heritage, Architecture in Macedonia,Skopje, LogosA 